\title{
A Study of Eddy Current Measurement (1986-1987)
}

Ram S. Ramachandran and Kenneth P. Armstrong

June 22, 1989

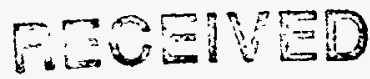

JUL 22 得领

OSTI

\section{MOUND}

operated by

S EGRL MOUND APPLIED TECHNOLOGIES

P.O. Box 3000, Miamisburg, Ohio 45343-0987

for the

U. S. DEPARTMENT OF ENERGY

Contract No. DE-AC04-88DP43495 


\section{DISCLAIMER}

Thls report was prepared as an account of work sponsored by an agency of the United States Government. Neither the Uniterd States Government nor any agency thereof. nor any of their employees. makes any warranty. express or implled. or assumes any legal Hablilty of responsibility for the accuracy. completeness. or usefulness of any information. apparatus. product: or process disclosed. or represents that its use would not infringe privately owned rights. Reference herein to any specific commerclal product. process. or service by trade name. trademark. manufacturer. or otherwise. does not necesserily constitute or imply its endorsement. recommendation. or favoring by the United States Government or any agency thereof. The views and opinions of authors expressed herein do not necessarlly state or reflect those of the United States Government or any agency thereof. 
MLM-MU-89-66-0003

\section{A Study of Eddy Current Measurement (1986-1987)}

Ram S. Ramachandran and Kenneth P. Armstrong

Issued: June 22, 1989

\section{MOUND}

\section{operated by}

EGIE MOUND APPLIED TECHNOLOGIES

P.O. Box 3000, Miamisburg, Ohio 45343-3000

for the

U. S. DEPARTMENT OF ENERGY

Contract No. DE-AC04-88DP43495 


\section{Contents}

\section{Page}



Introduction $\ldots \ldots \ldots \ldots \ldots \ldots \ldots \ldots \ldots \ldots \ldots \ldots \ldots \ldots \ldots$



Precision of Eddy Current Gaging of Thickness Memo $\ldots \ldots \ldots \ldots .4$

Receiving Inspection of Microclad Material Memo $\ldots \ldots \ldots \ldots \ldots 10$

Eddy Current Measurement Study Memo $\ldots \ldots \ldots \ldots \ldots \ldots \ldots \ldots 12$

Microclad Thickness Measurement Variation Memo ........... 17

MC3926 Bridge Thickness Variation Memo ............... 18

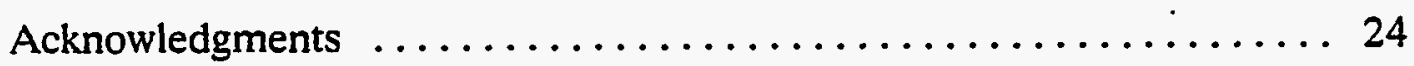

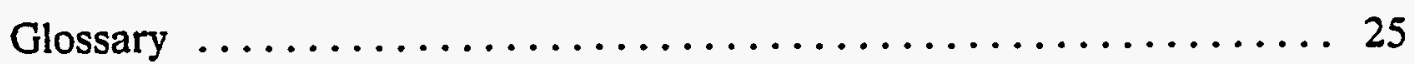

Distribution ................................... 27 


\section{Abstract}

A study was conducted in 1986 to evaluate a modified eddy current system for measuring copper thickness on Kapton. Results showed a measurement error of $0.42 \mu \mathrm{in}$. for a thickness range of 165 to $170 \mu \mathrm{in}$. and a measurement variability of $3.2 \mu \mathrm{in}$.

\section{Introduction}

The MC3926 and 1E38 detonators were developed based on studies conducted by Quality, Production, and Development personnel. In the early stages of the programs, the tape process studies were documented in memos. To formally record these studies and make them easily available to interested persons, these memos are being compiled as Mound technical reports. This report documents research performed by R. S. Ramachandran in 1986.

The eddy current system discussed in this report was used to determine the thickness of copper substrates on Kapton (microclad). It was used to perform receiving inspection thickness measurements on material from Fortin Industries. Microclad was used to fabricate slapper detonator bridges for which copper thickness is critical to detonator performance.

The measurement error for a thickness range of 165 to $170 \mu \mathrm{in}$. was found to be $0.42 \mu \mathrm{in}$. Measurement variability was determined to be $3.2 \mu \mathrm{in}$. ( 3 sigma). These results show a considerable improvement over previous studies and are a result of improvements in vibration reduction, probe temperature control, and fixture design.

\section{Content}

This report comprises five memos summarizing work performed in the tape process area. The memos are reproduced unedited. 
Mound

Inter-Office Correspondence

Fron: Experimental Design, Nuclear

Operations, S. E. Rigdon

Cc. D. B. Armstrong

Date: $\quad$ April 17, 1986

Subject: Precision of Eddy Current Gaging

of Thickness

Reference:

To:

R. S. Ramachandran

OBJECTIVE

The objective of this study was to determine the following components of variability of Eddy Current gaging of thickness: within day. day-to-day, unit-to-unit and measurement error.

\section{EXPERIMENTAL DESIGN}

Twenty five units were selected for gaging thickness. Each unit was measured once. Later the same day, each unit was measured again. This was then repeated four more times on four additional days. Thus, for each unit, one measurement was taken twice a day for five days giving ten measurements per unit.

\section{A.AALYSIS}


The model is assumed to be as follows:

$$
\text { THICKNESS }=\mu+\theta_{\text {UNET }}+\theta_{\text {DAY }}+\theta_{\text {WTTHIN DAY }}+\varepsilon
$$

where $\theta_{\text {UNTT }} \theta_{\text {.DAY }}, \theta_{\text {WTTHN DAY }}$ and $\varepsilon$ are normally distributed

with mean zero and variances $\sigma_{U N T^{\prime}}^{2} \sigma_{D A Y^{\prime}}^{2}$

$\sigma_{\text {WTTHN DAY }}^{2}$ and $\sigma_{\text {ERROR }}^{2}$ respectively. The following

estimates for these quantities were obtained:

$$
\begin{aligned}
& \hat{\sigma}_{\text {UNIT }}^{2}=0.121 \\
& \hat{\sigma}_{\text {DAY }}^{2}=0.644 \\
& \hat{\sigma}_{\text {WITHN DAY }}^{2}=0.0017 \\
& \hat{\sigma}_{\text {ERROR }}^{2}=2.966 .
\end{aligned}
$$

The largest single variance component is the measurer:'nt error. The attached plots show this clearly. The first plot, titled Scatter Plot of First and Second Thickness Readings' shows little correlation between the first measurement and the second measurement taken on each day. Ideally.

all measurements would lie on the $45^{\circ}$ ine. The second plot. titled 'Unit to Unit Variability in Thickness Readings' shows for each unit. the ten measurements made. For nearly all units, the measured thicknesses range from 165 to 170 . This plot indicates that the measurement error is much larger than the variability of the process which produced the units. The third plot tıtled 'Day to Day Varıbulity in Thickness Readings' shows the variability of the 25 units on each of the fire days.

\section{CONCLUSION}


Within the range of thicknesses considered, 165 to $1.70 \mu$ in., the Eddy

Current method of gaging thickness is quite variable. The overall

variability, excluding the process variability, is $\sigma_{\text {overall }}=1.90$

$\mu$ in.



Steve Rigdon 


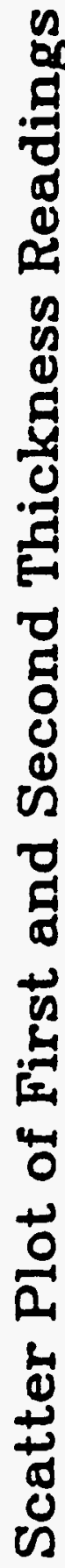

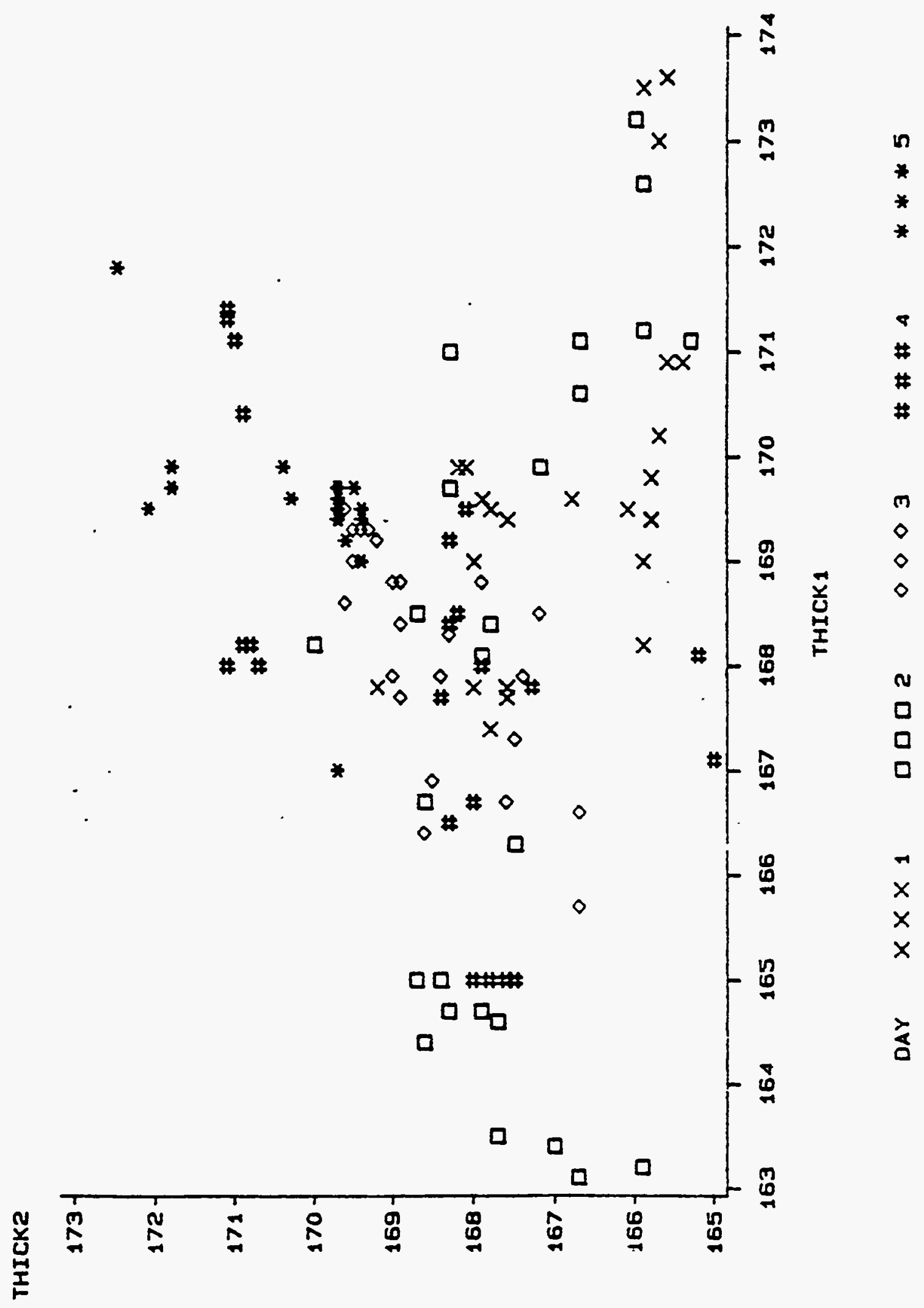



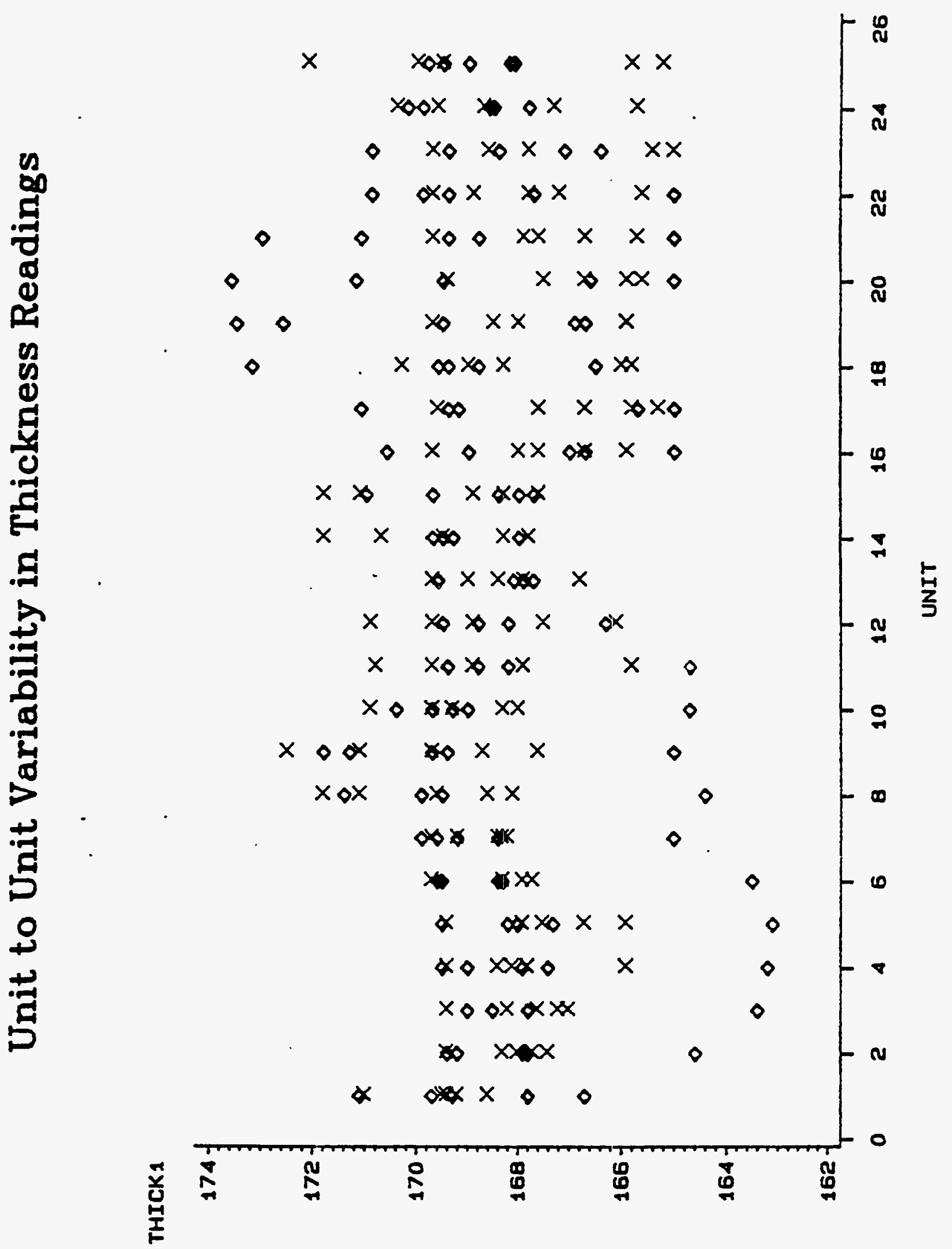


\section{Day to Day Variability in Thickness Readings}

THICK1






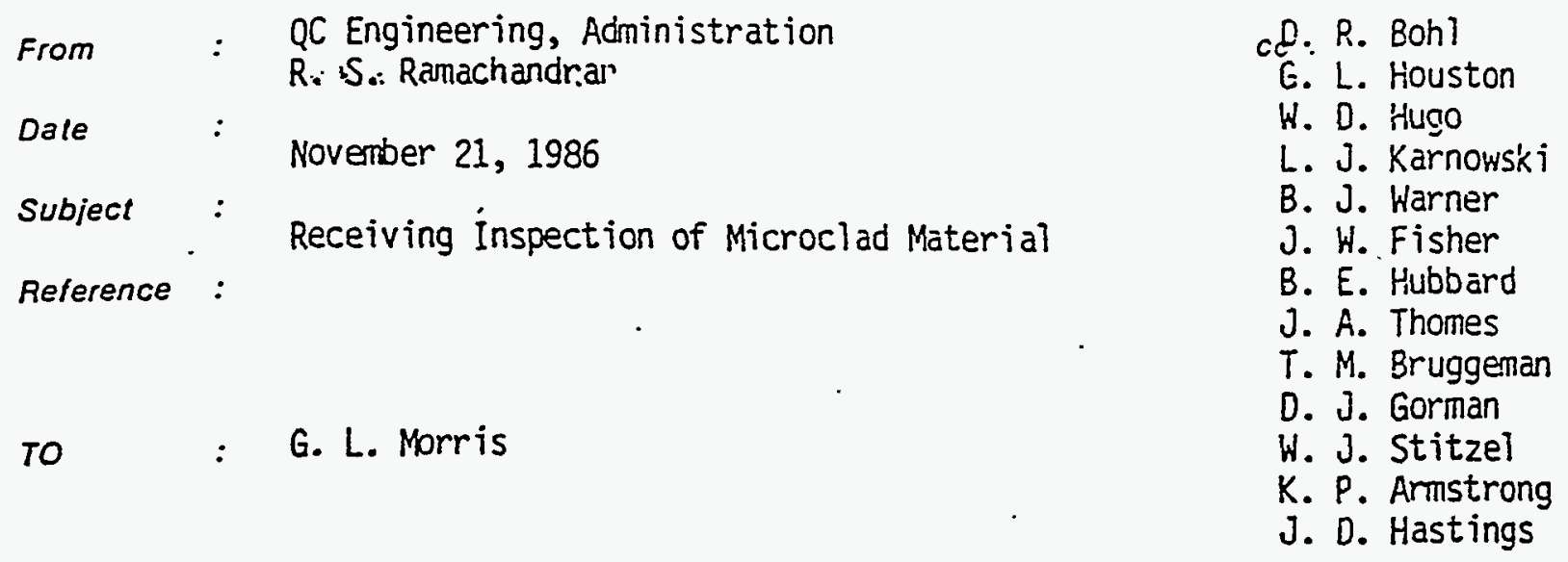

Qual lot production of $1 E 38$ bridges is scheduled for next week. Quality level of the microclad material needs to be verified prior to the production.

Eddy current instrument was modified for measurement improvement and the last study showed a significant improvement in precision and accuracy of the equipment. The test showed a measurement error of 0.42 microinches $m$ the PVD thickne:s ranging from -165 to 170 microinches. Total Imeasurement variability (excluding the process variation). was 3.2 microinches. The accuracy test $2 n$ six ranges of standards (75 to 170 microinches' - showed a maximum bias of $+/-2.5$ microinches.

We could use the eddy current instrument in DS-123 for the verification of the microclad material going into the qual production with the following limitations:

1. Standards for-calibration will be PVD material and there is a bias between the readings: of microclad and PVD.

2. An estimate of the absolute value of microclad material based on PVD calibration could be determined with a.small test of bridge material between Laseruler and Eddy current checks.

3. The acceptance specification of 150 to 200 microinches needs to be adjusted based on Item 2 above. -

4. Reliability of the data is based on the Accuracy and Precision study concluded from the 25 PVD.samples.

5. Eddy.current is :equipped with $35 \mathrm{~mm}$ reel to reel fixture operation. (12 inch width materials will have to be slit prior to QC acceptance testing).

6. A sampling criterion needs to be established. All incoming $35 \mathrm{~mm}$ reels with a certain number of checks per reel will be ideal. For the initial qual lot production, the reels will be measured randomly within every two feet - a total of approximately 50 readings/reel.

7. Receiving Inspection téchnician to be trained by the Component Development personnel. Scheduling of other technicians is also necessary. 
8. An operating procedure needs to be drafted. This will include set up procedure (standards and calibration before and after testing) and running of the test.

9. On a later date the eddy current instrument needs to be certified by Mound's Standards Lab.

An Accuracy and Precision study with microclad material is planned by $Q C$ Engineering and Mound is awaiting the master standards. Preparation of the standards for microclad material has been initiated with a round robbin study (Mound, LANL and Fortin) planned for early next year.

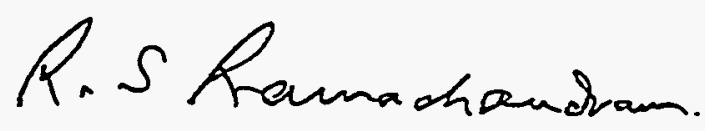

R. S. Ramachandran 


\begin{tabular}{|c|c|c|c|c|}
\hline From & : & $\begin{array}{l}\text { Administration, Quality Engineering } \\
\text { R. S. Ramachandran, S. E. Rigdon } \\
\text { December } 3.1986\end{array}$ & $c c:$ & $\begin{array}{l}\text { G. L. Houston } \\
\text { R. J. Finney } \\
\text { W. D. Huao }\end{array}$ \\
\hline Date & : & veceniver s, 1900 & & D. B. Armstrong \\
\hline Subject & : & Eddy current Measurement Study & & $\begin{array}{l}\text { B. E: Hubbard } \\
\text { J. D. Hastings }\end{array}$ \\
\hline Reference & : & & & $\begin{array}{l}\text { J. R. Brinkman } \\
\text { D. R. Bohl } \\
\text { D. L. Coffey } \\
\text { B. J. Warner }\end{array}$ \\
\hline TO & 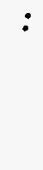 & G. L. Morris & & $\begin{array}{l}\text { J. A. Thomes } \\
\text { K. P. Armstrong } \\
\text { L. J. Karnowski } \\
\text { J. C. Hanna }\end{array}$ \\
\hline
\end{tabular}

Sumary: A statistical study from the modified Eddy Current test instrument showed an improvement in the measurement error from 1.72 to 0.42 microinches in the PVD thickness ranging from 165 to 170 microinches. Total-measurement variability (excluding the process variability) improved by $40 \%$ ( 5.7 vs. 3.2 microinches - 3 sigma) with the reduction of vibration of Eddy Current equipment, control of the probe temperature and fixture redesign for positive hold of the PVD samples. The accuracy study on six ranges of standard (75 to 170 microinches) showed a maximum bias of $+/-2.5$ microinches.

Background: The previous conclusion from the Eddy Current method of gaging thickness was that the measurements were quite variable. The overall measurement variability of Eddy Current gaging of thickness was 0.4 times the product tolerance and the measurement error was determined to be much larger than the process variability. Accuracy of the instrument (ability to measure PVD materials) was a maximum of 8.9 microinches. The test run also indicated a shift in the calibration and the data showed a day-to-day variation.

Design of Experiment: The same twenty five PVD units, used in the previous test (Aprit 1986), were selected for this repeat study. Each unit. was measured twice a day, morning and afternoon, for five days giving ten measurements per unit. The six PVD standards were also measured as above for accuracy determination.

Results of the analysis:

1. Analysis of variance showed a significant ( $F$ ratio values) difference between the following observations. Refer to the attached table \#1.

a) The first readings and the second readings (measurements in the mornings were higher than the afternoon measurements) indicate a time effect. From figure \#1 it could be seen that the first

b) readings are higher (except for Day \#3) than the second readings.

b) Day-to-day variability is real.

c) Not all units are the same. 
Results of the Analysis: (Contd.)

2. The precision study showed an improvement from the April 1986 measurement tests (refer to the attached table \#2).

a) Measurement error improved from 1.72 to 0.42 microinches in the range of PVD thickness 165 to 170 microinches.

b) Total measurement variability improved from 1.90 to 1.06 microinches with the modification of the measuring equipment.

3. Accuracy study on six standards, ranging from 75 to 170 microinches, showed a maximum bias of 2.5 microinches (see attached figure \#2).

4. Measurement capability of the Eddy Current barely detects the large to small measurements of true process as determined from the ratio of total measurement variability to unit-to-unit variability (1.22). In other words, the instrument is not sensitive enough to detect smali variations or the process is too good to give large variations.

\section{Recommendations:}

1. Preparation of a microclad standard for measurement of tape processing raw material should.be expedited.

2. Staging station for microclad and reel-to-reel fixture need redesign for improving the stability of measurements.

3. Improvements in the systems electrical noise levels need to be studied. This could involve replacement of existing computer.

4. Further study to improve calibration shift in levels within the system needs attention.

5. A measurement capability study with microclad material testing on the Eddy Current needs to be initiated. Determine accuracy and precision with microclad material to include copper impurity and microscopic voids in the raw material.

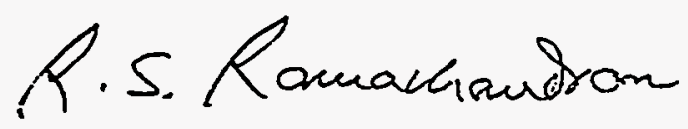

R. S. Ramachandran

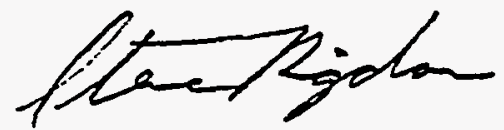

S. E. Rigdon 


\section{TABLE 1}

ANALYSIS OF VARIANCE

EDDY CURRENT MEASUREMENT STUDY

\section{SOURCE}

Unit

Day

Time (Day)
$\underline{D F}$

24

4

5

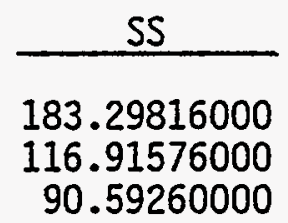

90.59260000
F VALUE

42.56

162.87

100.96

\begin{tabular}{l}
$P R>F$ \\
\hline 0.0 \\
0.0 \\
0.0
\end{tabular}

\section{TABLE 2 \\ ESTIMATED STANDARD DEVIATION}

EDDY CURRENT PRECISION STUDY

Source

Unit-to-Unit

Day-to-Day

Time-to-Time Within Day

Measurement Error

Total Variability

Total Measurement Variability
Current Study

0.864

0.471

0.847

0.424
April Study

0.348

0.802

0.041

1.722
1.365

1.932

1.057

1.900 
Precision Study on Eddy Current Gaging of Thickness Scatter Plot of First and Second Thickness Readings by Day

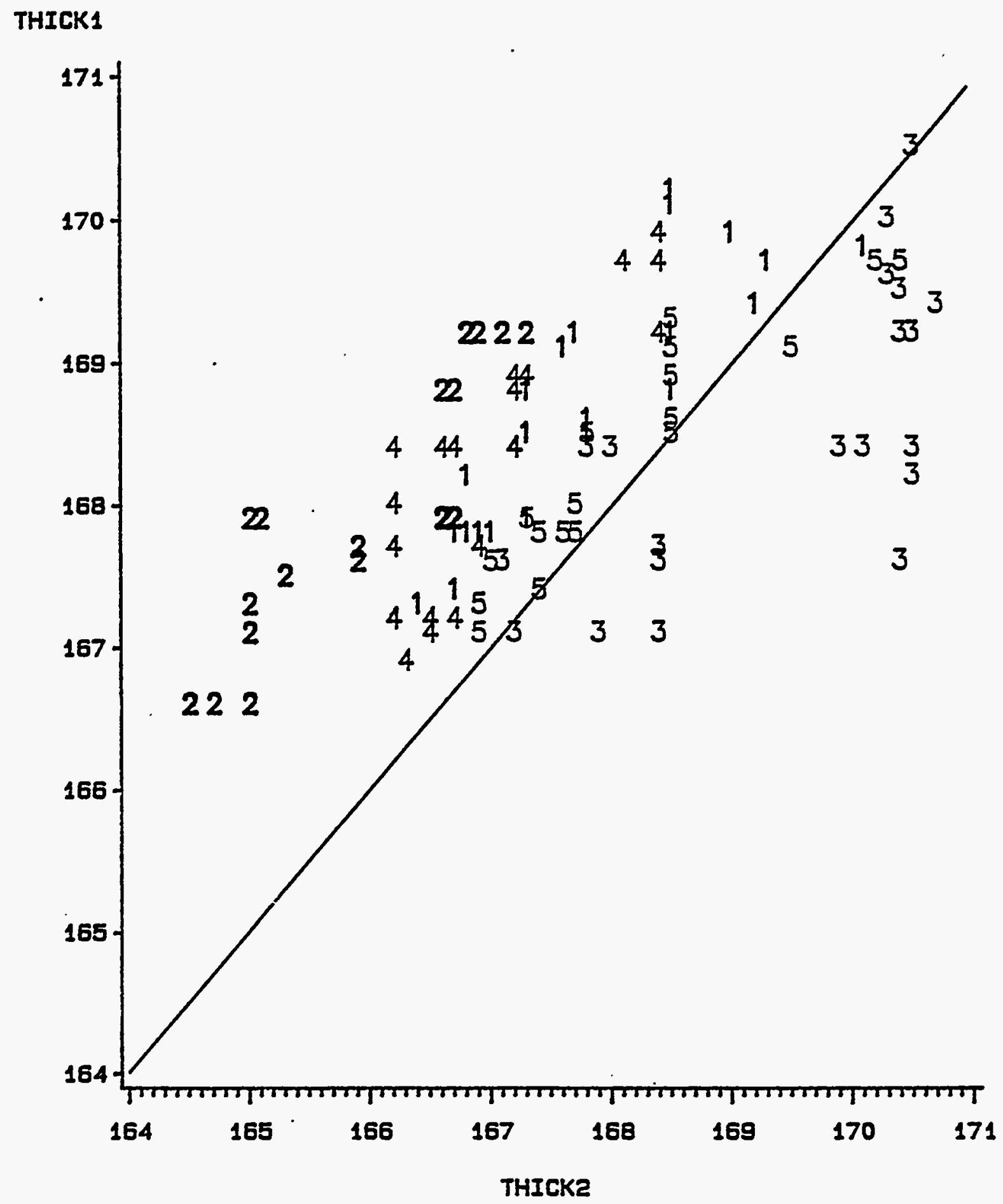

DAY $11112222 \quad 3333 \quad 4444 \quad 5555$ 
Accuracy (Bias) Study on Eddy Current Gaging of Thickness Run Chart of Bias from Measurements on Standards

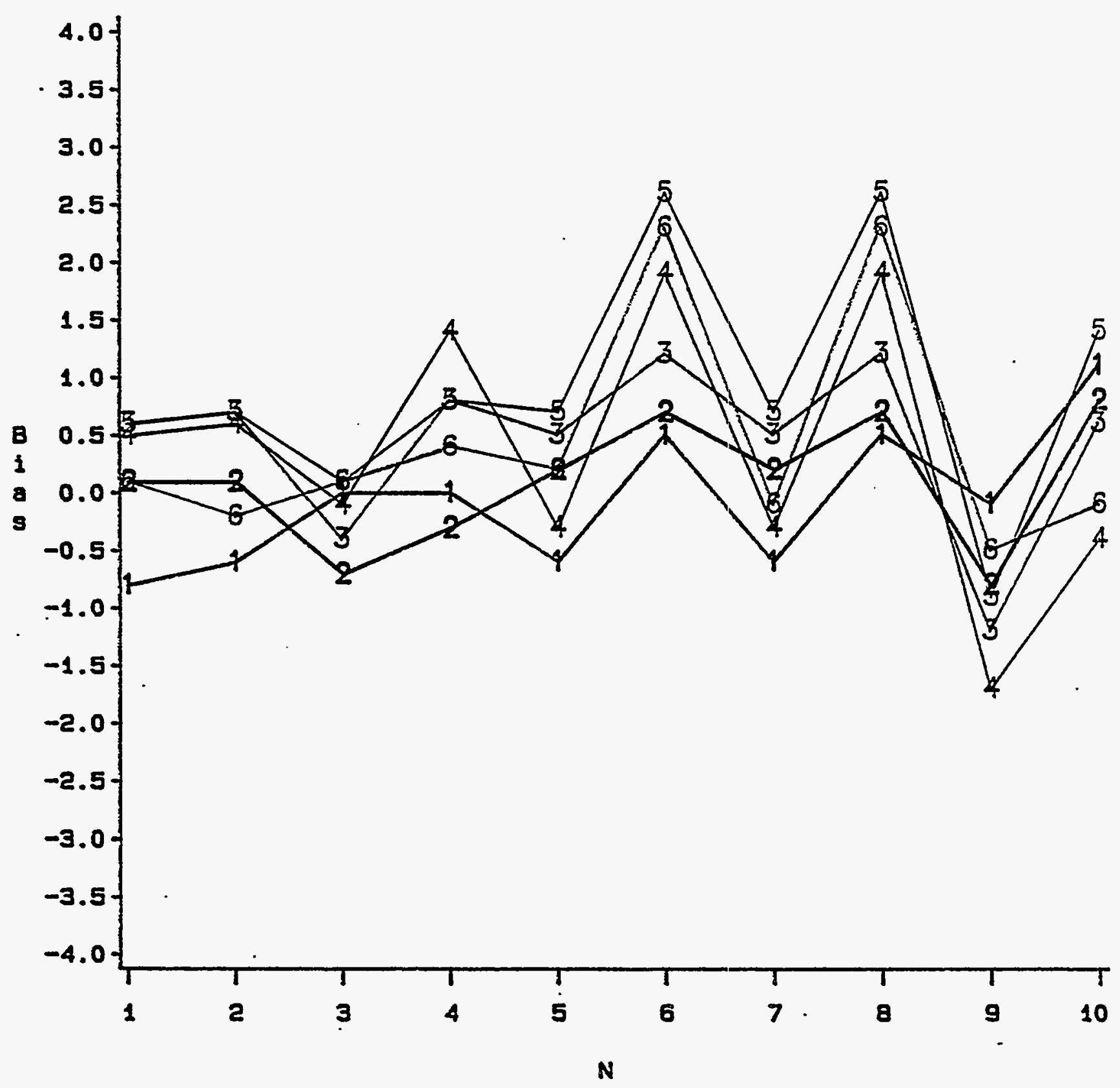




$\begin{array}{llr}\text { From } & : \text { R. S. Ramachandran } & \text { cc: S. Houston } \\ \text { Qual ity Engineering } & \text { L. Karnowski } \\ \text { Date } & : \text { December 5, 1986 } & \text { G. Morris } \\ \text { Subject } & \text { Microclad Thickness Measurement } & \text { D. Hastings } \\ & \text { Variation - Eddy Current } & \text { J. Fisher } \\ \text { Reference }: \text { R. Finney } & \text { D. Bohl }\end{array}$

The analysis of two sets of data generated after the modification of staging station vacuum attachment and electrical systems checks are summarized below:

Test \#1

Repeatability of eddy current to measure the copper microclad material ranging from $143-149$ microinches is 0.922 microinches $(0.6 \%)$. This is calculated from the three replicate readings at 10 locations of the tape reel-\#1-1 (QC \#36396).

\section{Test \#2}

a. Measurement variability including the process variation is 12.07 microinches for the mean thickness of 142.9 microinches (range 134.04-150.18 microinches).

b. Measurement variation within 6" strips of microclad samples (including the process variation) is 6.10 microinches.

These calculations are made from 15 subgroup measurements from five 6" strip materials.

It should be noted that the instruement was calibrated with PVD standards (134.3, 169.7 and 200.6 microinches) and there appears to be a significant bias in the absolute value from the tested assumed 175 microinches material.

The ratio of measurement capability of eddy current to product tolerances is about four (4). Good reference materials for microclad materials are required to minimize the bias. Efforts are underway to determine the thickness level of the sample - Betaback scatter and $x$-ray fluorescence method of measurement.

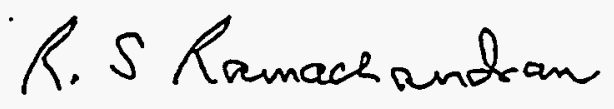
R. S. Ramachandran

RSR : sj 


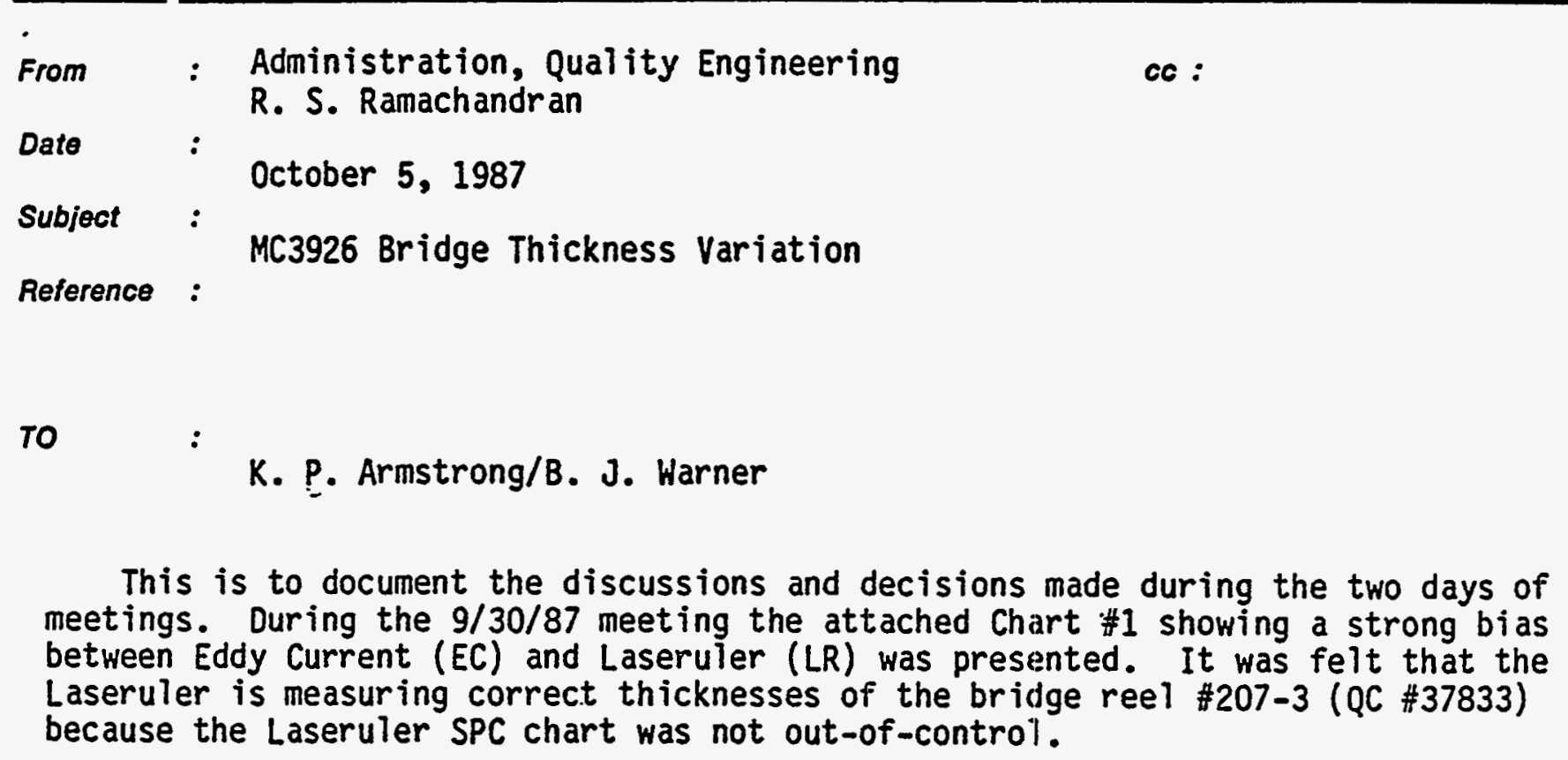

We knew that the EC bias is not constant and the correction factor could be either a product or a sum. Also the "Variable Bias" needs to be established for every batch or shipment from the vendor to determine the true level of copper thickness. This is because Eddy Current measures conductivity of the bridge material and is affected by the density, composition, impurities, voids and scratches on the material.

As for the verification of the thickness data, during the 10/1/87 meeting, additional information (Chart \#2) on the same 26 bridges measured by $X$-Ray Fluorescence (XRF) and Beta Backscatter (BB) techniques were presented. It is very evident that the LR measurement level is that of XRF thickness measurement. XRF has a higher level of detection sensitivity and gives a better precision than LR (See Table 1).

It should be noted that EC measurement level did not change from the past materials but the actual thickness is higher. Now, the question is, has the material changed from the previously accepted raw material in composition or impurities?

The fluctuation in $B B$ readings is due to the instrument instability and use of a new source (Lithium 147). It takes about 6 to 8 hours of warm up time and as the source decays, the output value will change. It was for a quick study, in determining the $B B$ level of measurement, this data was generated. For a good comparison of vendor $B B$ results with Mound $B B$ data, a round robin test needs to be designed. 
Armstrong/Warner

October 5,1987

The Microclad Standards from Laseruler were checked for thickness measurements on the four measuring systems with no significant differences (Table 2). This confirms that all the four systems are good for measuring thicknesses and for our application, XRF is the best.

The final conclusions were:

1. Accept the Laseruler data and disposition the bridges accordingly.

2. It is tedious to establish the EC "Variable Bias" for each batch of raw material received. Discontinue EC technique for Tape Lab. bridge material acceptance.

3. Move the XRF from $T$ building (W. Dudley's office) to OS building and train technicians to perform the thickness of microclad copper raw materials for QC acceptance.

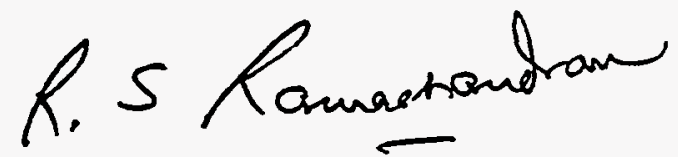

R. S. Ramachandran 
MC3926 Bridge Thickness Measurements






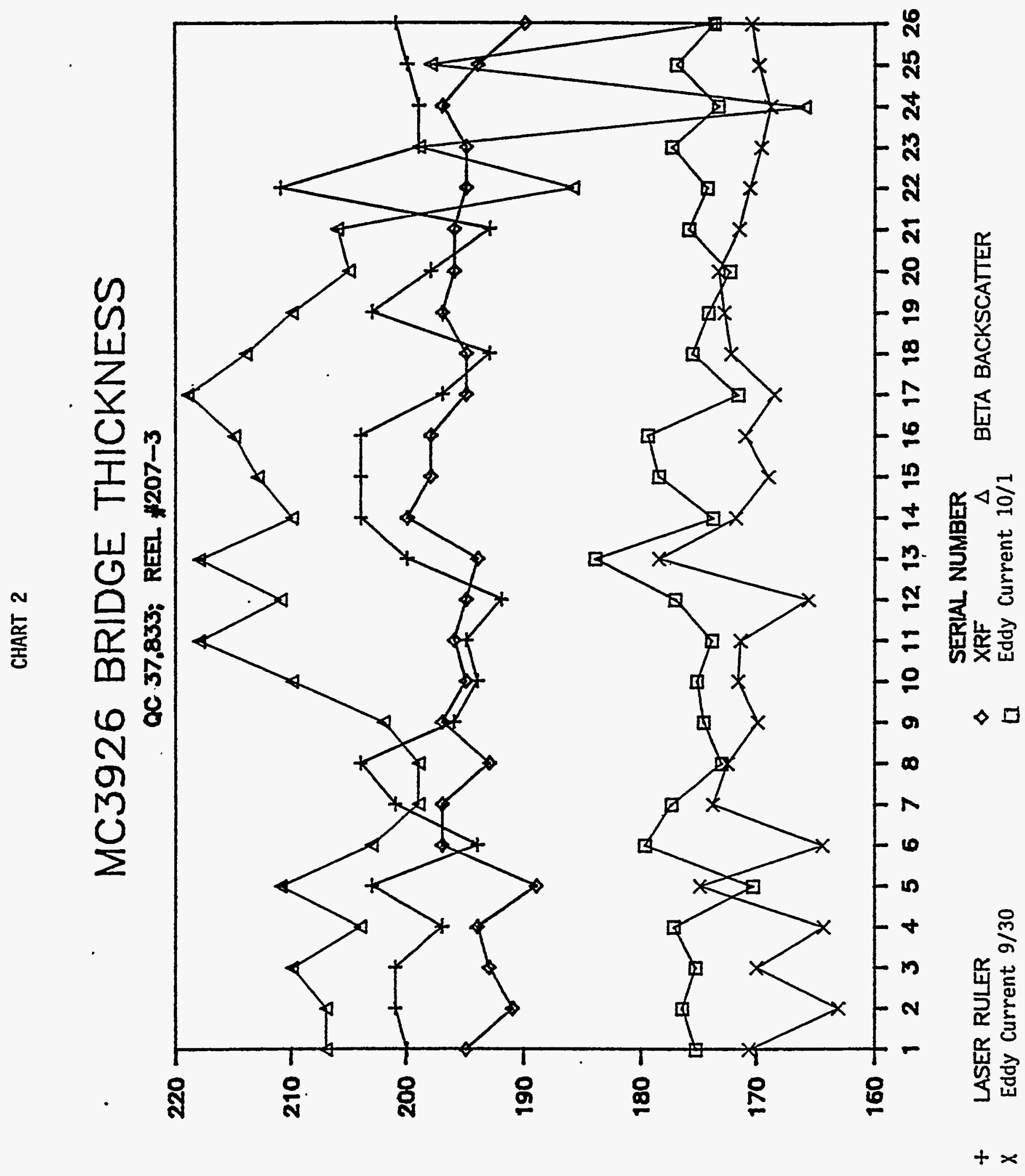

(SבHONIO\&OIW) SSINYOIHL 
TABLE 1

YC3926 BRIDGB IHICXXISS ( PC137833, Reel 1207-3)

D0. ID IC $9 / 30$ BC+32 BC 10/1 BC+32 LB IRI BB

$\begin{array}{rrrrrrrrr}1 & 5273 & 138.7 & 170.7 & 143.3 & 175.3 & 200 & 195 & 207 \\ 2 & 5271 & 181.1 & 163.1 & 144.5 & 176.5 & 201 & 191 & 207 \\ 3 & 5275 & 138 & 170 & 143.3 & 175.3 & 201 & 193 & 210 \\ 1 & 5276 & 132.3 & 164.3 & 145.2 & 177.2 & 197 & 194 & 204 \\ 5 & 5277 & 142.9 & 174.9 & 138.3 & 170.3 & 203 & 189 & 211 \\ 6 & 5278 & 132.4 & 164.4 & 147.7 & 179.7 & 194 & 197 & 203 \\ 7 & 5279 & 141.8 & 173.8 & 145.4 & 177.4 & 201 & 197 & 199 \\ 8 & 5280 & 140.5 & 172.5 & 141 & 173 & 204 & 193 & 199 \\ 9 & 5281 & 137.9 & 169.9 & 142.6 & 174.6 & 196 & 197 & 202 \\ 10 & 5282 & 139.6 & 171.6 & 143.2 & 175.2 & 191 & 195 & 210 \\ 11 & 5283 & 139.4 & 171.4 & 141.9 & 173.9 & 195 & 196 & 218 \\ 12 & 5281 & 133.6 & 165.6 & 145.1 & 177.1 & 192 & 195 & 211 \\ 13 & 5285 & 146.5 & 178.5 & 152 & 184 & 200 & 194 & 218 \\ 14 & 5286 & 139.8 & 171.8 & 141.8 & 173.8 & 204 & 200 & 210 \\ 15 & 5289 & 137 & 169 & 146.5 & 178.5 & 201 & 198 & 213 \\ 16 & 5288 & 139 & 171 & 147.5 & 179.5 & 204 & 198 & 215 \\ 17 & 5289 & 136.5 & 168.5 & 139.6 & 171.6 & 197 & 195 & 219 \\ 18 & 5290 & 140.2 & 172.2 & 143.6 & 175.6 & 193 & 195 & 214 \\ 19 & 5291 & 140.8 & 172.8 & 142.2 & 174.2 & 203 & 197 & 210 \\ 20 & 5292 & 141.3 & 173.3 & 140.3 & 172.3 & 198 & 196 & 205 \\ 21 & 5293 & 139.5 & 171.5 & 143.9 & 175.9 & 193 & 196 & 206 \\ 22 & 5291 & 138.6 & 170.6 & 142.3 & 174.3 & 211 & 195 & 186 \\ 23 & 5295 & 137.6 & 169.6 & 145.1 & 177.4 & 199 & 195 & 199 \\ 21 & 5296 & 136.8 & 168.8 & 141.3 & 173.3 & 199 & 197 & 166 \\ 25 & 5297 & 137.8 & 169.8 & 145 & 177 & 200 & 194 & 198 \\ 26 & 5298 & 138.4 & 170.1 & 141.7 & 173.1 & 201 & 190 & 174\end{array}$

drerage

Std.Der.

Bigh

Lor
$138.3846170 .3846 \quad 143.6384175 .6384199 .3846195 .0769204 .3846$ 3.3729143 .3729142 .8765362 .8765364 .4549022 .48069412 .59230 $\begin{array}{lllllll}146.5 & 178.5 & 152 & 184 & 211 & 200 & 219\end{array}$ $\begin{array}{lllllll}131.1 & 163.1 & 138.3 & 170.3 & 192 & 189 & 166\end{array}$ 


\section{TABLE 2}

MICROCLAD STANDARDS COPPER THICKNESS MEASUREMENTS IN Uin.

\begin{tabular}{|c|c|c|}
\hline & Master & Standards \\
\hline & $8-800$ & $027-27$ \\
\hline Certified & 168 & 200 \\
\hline Uncertainty & 2 & 3 \\
\hline Laseruler & 171.5 & 199.5 \\
\hline Eddy Current +32 & 169.6 & - \\
\hline X-Ray Eluorescence & 168 & 201 \\
\hline Beta Backscatter & 166 & 203 \\
\hline
\end{tabular}

RSR/10-5-87 


\section{Acknowledgments}

The authors would like to thank S. E. Rigdon and B. E. Hubbard for their contribution to tape process development. The authors also extend special recognition to those Production, Quality, and Development personnel who contributed to the data collection and reduction. K. P. Armstrong claims no recognition for the research, only for the effort required to document it. 


\section{Glossary}

Artwork

Bridge

Bridge Length

Bridge Width

Eddy Current

Flyer

Kapton

LANL

Laseruler

LLNL

Microclad

Phototool

Radius Bridge

Reel

Receiving Inspection

Roll
See phototool.

Functioning copper foil portion of a slapper that drives the flyer.

Dimension of a bridge parallel to the electric current.

Dimension of a bridge perpendicular to the electric current.

Nondestructive technique for measuring substrate thickness; used to determine copper thickness on bridge (microclad) material.

Portion of a slapper detonator driven by rapid ionization of the bridge element (usually 0.001 -in. to 0.002 -in. Kapton).

Trade name for a polyimide product produced by duPont.

Los Alamos National Laboratory.

Tool used to nondestructively measure substrate thickness; used to determine copper thickness on finished bridge circuits.

Lawrence Livermore National Laboratory.

Trade name of a copper-coated polyimide produced by Fortin Industries and used in fabricating bridges and flyers.

Tool used to create a circuit image. A phototool contains the image of the desired circuit and exposes the image onto a chemically conditioned surface.

Bridge for which the length is defined by a radius such that the center of the bridge is in the thinnest region.

Sample of material slit to a width of $35 \mathrm{~mm}$ and wound around a core.

Area at Mound where incoming material is inspected for conformance to specifications.

Sample of material as purchased from a vendor. A roll is the original width, usually 12 in. A roll is later slit to thinner widths to become reels. 
SNLA

Square Bridge

Tape Process

Vidicom

Wet Processing
Sandia National Laboratories, Albuquerque.

Bridge for which the width is uniform from end to end.

Method of producing flexible circuits in a reel-to-reel fashion. This process is unique to Mound.

Vision system produced by Vidicom to inspect bridge length and width.

Process of laminating, exposing, developing, etching, and stripping a flexible circuit image. 


\section{Distribution}

\section{External}

S. G. Barnhart, Sandia National Laboratories, Albuquerque

G. E. Dahms, Sandia National Laboratories, Albuquerque

R. McCormick, Los Alamos National Laboratory

J. A. Morley, DOE/DAO

\section{Internal}

K. P. Armstrong

J. R. Brinkman

T. M. Bruggeman

T. A. Demana

R. A. Fischbein

M. P. Fisher

E. D. Freese

E. D. Hill

G. L. Houston

M. A. Huelskamp

C. W. Huntington

D. P. Kelly

D. E. Michel

G. L. Morris

R. S. Ramachandran

M. D. Stoltz

J. A. Thomes

R. E. Vallee

S. I. Waskey

W. Yurkowsky, Jr.

Library (10)

Publications 